\title{
Advances in Hypergolic Propellants: Ignition, Hydrazine, and Hydrogen Peroxide Research
}

\author{
Stephen M. Davis and Nadir Yilmaz \\ Department of Mechanical Engineering, New Mexico Institute of Mining and Technology, Socorro, NM 87801, USA \\ Correspondence should be addressed to Nadir Yilmaz; yilmaznadir@yahoo.com
}

Received 6 June 2014; Accepted 27 August 2014; Published 15 September 2014

Academic Editor: Kazhikathra Kailasanath

Copyright ( 2014 S. M. Davis and N. Yilmaz. This is an open access article distributed under the Creative Commons Attribution License, which permits unrestricted use, distribution, and reproduction in any medium, provided the original work is properly cited.

A review of the literature pertaining to hypergolic fuel systems, particularly using hydrazine or its derivatives and hydrogen peroxide, has been conducted. It has been shown that a large effort has been made towards minimizing the risks involved with the use of a toxic propellant such as the hydrazine. Substitution of hydrazines for nontoxic propellant formulations such as the use of high purity hydrogen peroxide with various types of fuels is one of the major areas of study for future hypergolic propellants. A series of criteria for future hypergolic propellants has been recommended, including low toxicity, wide temperature range applicability, short ignition delay, high specific impulse or density specific impulse, and storability at room temperature.

\section{Introduction}

In typical combustion systems an ignition source such as a spark is needed to begin the combustion reaction [1]. In rocket propellants, there exists a class of materials which ignites spontaneously without the need for an ignition source. A combination of two materials which self-ignites at room temperature is called hypergolic. Because they do not require external ignition forces (compression, spark, heating, catalytic decomposition, etc.), hypergolic mixtures need only a valve to mix the fluids and initiate combustion. This simple mechanism for controlling combustion reduces the number of components in the ignition system which reduces the statistical chances for failure as well as the payload of the system relative to nonhypergolic systems. Therefore, such a system with few mechanical parts and low weight is particularly favorable to extraterrestrial craft.

There are several quantifiable properties which are important in any propellant system including specific impulse (the thrust per weight of propellant) and adiabatic flame temperature [2]. Additionally, one of the most important quantities for a hypergolic propellant is the ignition delay, the time between fluid contact and ignition; alternatively, the chemical ignition delay may be used, where the time between the onset of vaporization and ignition is utilized as defined in $[3,4]$. In $[5,6]$ these delay times are used, in part, to describe the preignition behavior of hypergolic propellants. Regardless of definition the time to ignition is important to the performance of a rocket propellant where a long delay leads to combustion outside of the combustion chamber or causes hard-starts, whereas a very short delay risks damaging the injection nozzle [7].

\section{Ignition Measurements}

There are two main techniques utilized to measure the ignition delay of a hypergolic mixture, the open cup (or drop test) and an engine test (or impinging jet). In the former a pool of one component (typically the oxidizer) is placed below a dropper containing the other component (the fuel). The measurement for the ignition delay may be taken in two different ways: (1) by recording the break in a laser [3, 4] and (2) visually by using a high speed camera to record the contact of the fluids and then the onset of light due to reaction $[3,5,8]$. In [6] a photodiode was used to set the ignition time rather than a high-speed camera, while recording the onset of boiling with a laser system as described in $[3,4]$. A diagram of the laser measurement system is depicted in 


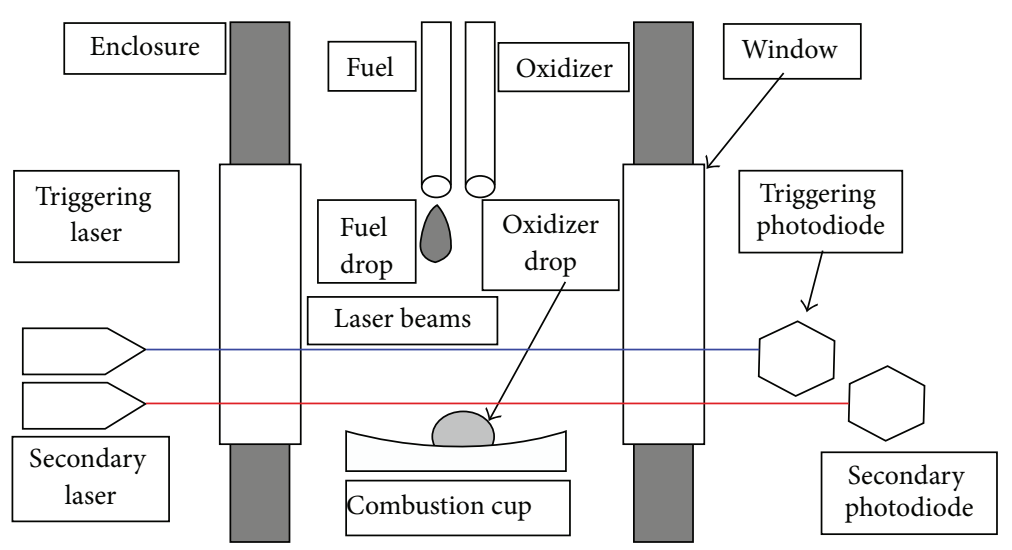

FIGURE 1: Basic setup for ignition delay measurement of hypergols [4].

Figure 1. As seen in Figure 1, a laser is mounted above a pool of oxidizer. When the fuel droplet passes through this laser beam the recording system is triggered. The fluctuations in the laser signal due to the evaporation of the fluid mixture are also recorded and define the onset of measurement for chemical delay. The ignition point is defined where the laser signal gets a boost from the production of heat and light $[3,4]$. The chemical delay time is preferred by many researchers as it eliminates the mixing factors which affect the reaction delay $[3,4,6]$. The chemical delay is measured in much the same way as the ignition delay, but is measured as the time between vaporization of the fuel and light ignition, thus minimizing the physical mixing aspects of preignition $[3,4,6]$.

In [4], the chemical and physical chemical delay times were compared revealing that a significant amount of preignition time is involved in mixing and heating the fluids to boiling. It is also shown in [4] that for oxidizer tot fuel ratios between one and four have little effect on the delay time; outside this range mixing was worse and the delay times were less consistent. Using an optical system, [5] was able so show three distinct regions to the preignition of monomethylhydrazine with nitric acid in conjunction with fine-wire thermocouples. These regions are (1) heating of the fluids up to the boiling point, (2) slower heating from boiling to $280^{\circ} \mathrm{C}$, and (3) rapid heating from $280^{\circ} \mathrm{C}$ to ignition.

In addition to the drop test, impinging jet and engine tests may be utilized to measure the ignition delay. These tests are often preferable over the drop test because they evaluate the hypergolic ignition delay under conditions more closely resembling service in a rocket thruster [7]. In the impinging jet test, the two components are mixed as they are injected into a combustion chamber, and as before, the ignition delay is defined as the time between stream impingement and ignition as seen using high speed cameras [8]. Figure 2 is a diagram of an impinging jet apparatus. One advantage of this test is the ability to evaluate environmental effects (temperature, pressure, thermal conductivity, etc.) have on the ignition delay [8].

Engine tests differ from impinging jet tests in a couple of ways. First, the ignition delay is measured using the chamber pressure [7]. In engine tests the time to $90 \%$ steady-state combustion chamber pressure is defined as the ignition point [7].
According to Slocum-Wang et al. [7], the preignition times of an engine test correlate well to the time-to-vaporization observed in drop tests, but drop tests cannot provide any information on hard starts or pressurization times. Due to this, it was recommended by Pourpoint and Anderson [8] that the drop test be utilized only as a prescreening tool for potential hypergolic propellants [8].

Due to the extreme importance of ignition delay to the operation of a propellant system the effects the environment has on the system must be understood. By observing the ignition of high test peroxide (HTP) with Block 0 (a mixture of methanol, water, manganese dioxide and acetic acid, made by dissolving manganese acetate tetrahydrate in water) it was determined that the pressure dependence on ignition delay for liquid hypergols is inversely proportional to the log of the pressure [8]. However, this correlation is only slightly better than for a linear regression. The thermal conductivity and diffusion coefficient of the ambient atmosphere plays a minor role in the ignition delay; however, increasing the ambient diffusion coefficient and thermal conductivity increase the ignition delay slightly. As expected from global reaction kinetic analysis, the higher the concentration of the reactants the faster the reaction may take place and the lower the ignition delay [8].

The preignition chemistry of 1-ethyl-3-methyl-imidazolium dicyanamide with $70 \%$ nitric acid was studied by Chowdhury et al. [9] in order to validate a new instrument designed to examine hypergolic ignition using Fourier Transform Infrared Spectroscopy (FTIR) and Confined Rapid Thermolysis (CTR) [9]. Under isothermal conditions $\left(90^{\circ} \mathrm{C}\right)$ it was discovered that the major condensed-phase reaction products included $\mathrm{CO}_{2}, \mathrm{H}_{2} \mathrm{O}$, and $\mathrm{N}_{2} \mathrm{O}$. Chowdhury et al. [9] were unable to identify the initial products of the gas-phase reaction and therefore recommended that further tests be used to identify these species [9].

The examination of preignition chemistry was also explored for mixtures of monomethyl hydrazine $(\mathrm{MMH})$ and nitrogen tetroxide (NTO) using computer modeling techniques [10]. Molecular dynamics simulations involving CarParrinello Molecular Dynamics suggest that the initial reaction between MMH and NTO produces methyl diazene and later dimethyl tetrazane and methyl triazine. Frank et al. [10] 


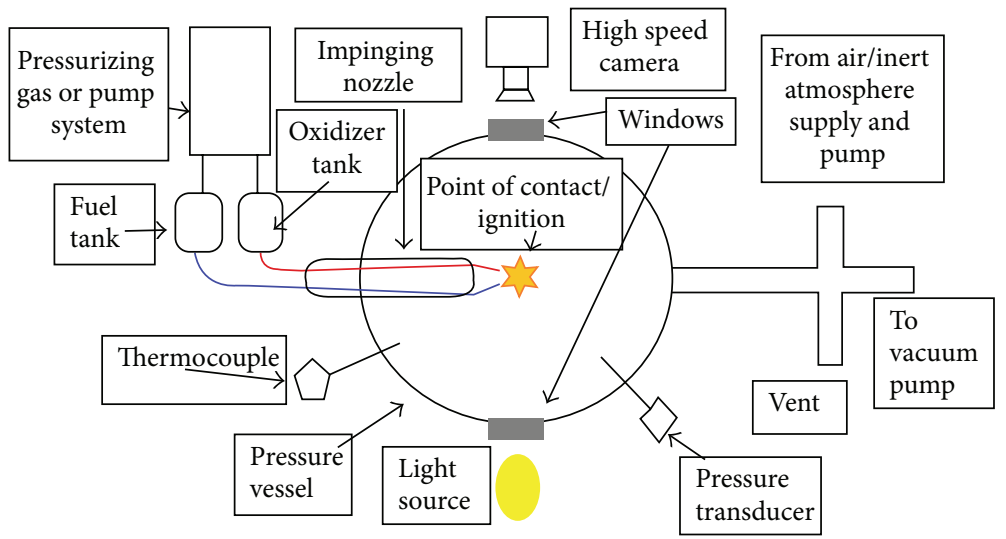

FIgURE 2: Basic setup for impinging jet ignition delay test [8].

then suggest that nitrate and azide salts of methylhydrazine compounds could be produced during low-temperature reactions [10]. These species would be important in pulsed reactors and pulsed rockets, the buildup of which may lead to explosive events during successive firings [10].

\section{Hydrazine-Based Hypergolics}

Hydrazine-based hypergolic propellants are among the first and most widely used hypergolic propellants [2, 11, 12]. Hydrazine, monomethylhydrazine $(\mathrm{MMH})$, unsymmetrical dimethylhydrazine (UDMH), and Aerozine 50 (50/50 mixture of hydrazine and UDMH) have been utilized by USA, Brittain, and Russia for several extraterrestrial craft; including the Nike Ajax missile, the Titan 2, various thrusters produced by Aerojet Co., and the maneuvering thrusters of the space shuttles $[11,12]$. When these fuels are used in combination with concentrated nitric acid or nitrogen tetroxide (NTO, $\mathrm{N}_{2} \mathrm{O}_{4}$ ) as oxidizers their performance is substantially better than hydrazine-based monopropellants [2, 11, 12]. Hypergolic hydrazine propellants are also preferred over cryogenic propellants such as liquid oxygen (LOX), where cryogenic propellants are difficult to store long term $[2,12]$.

Despite the history of hydrazine usage; the physiochemical aspects of its hypergolic activity are not fully understood. Because hypergolic reactions are spontaneous and rapid, it is difficult to study the reaction through conventional means such as shock tube experiments. Instead, recent efforts have been made to explore the reactions of hydrazine and its derivatives using a combination of spectrometry, spectroscopy, high speed photography, and computer simulations.

High speed photography studies performed by Wang and Thynell [5] and by Catoire et al. [13] have suggested that $\mathrm{MMH}$ reacts hypergolically with nitric acid and $\mathrm{N}_{2} \mathrm{O}_{4}$ in three- or two-stage combustion reactions, respectively $[5,13]$. Fourier transform infrared spectroscopy and time-of-flight mass spectrometry (ToFMS) suggest that when liquid MMH comes into contact with nitric acid the two begin reacting immediately forming monomethylhydrazine nitrate, methyl azide, and methyl nitrate, with small amounts of $\mathrm{N}_{2} \mathrm{O}, \mathrm{H}_{2} \mathrm{O}$ and $\mathrm{N}_{2}$. These products are formed exothermically, leading to an increase in temperature until the liquids are vaporized and the monomethylhydrazine nitrate is aerosolized (stage two). In the third stage, the system continues to heat up to approximately $280^{\circ} \mathrm{C}$, when the monomethylhydrazine nitrate begins to decompose into the final reaction products. It is in this third stage that the combustion reaction begins to produce light, and ignites $[5,13]$.

In contrast, when gaseous $\mathrm{MMH}$ and NTO come into contact, they produce a whitish-yellow fog prior to ignition [13]. This fog forms regardless of whether the system will ignite or not, and is controlled by the pressure and mixing ratios of the gases. When the system ignites two different instances of light production are observed; the first light is produced over the whole gas volume and the second from a distinct location that then propagates through the rest of the gas. It has been proposed that the first instance of light production is induced by the exothermic reaction of the fog formation, because the fog itself is not chemiluminescent. Because the second light production is more localized, it was suggested that this was the initial flame kernel [13].

Various thermodynamic and quantum chemical simulations have been performed in order to try and explain how hydrazine bipropellants react and to determine the most important mechanisms responsible for self-ignition. However, before a valid model can be developed to explain the reaction from liquid hydrazine to gaseous combustion products, a detailed understanding of the thermodynamics of hydrazine is first required. In 2002, a model based on the Claussius equation and the Helmholtz potential was developed in order to accurately predict the liquid-vapor phase changes of hydrazine [14]. This modified Claussius equation model correctly predicts the hydrazine liquid-vapor phase equilibrium from $273.15 \mathrm{~K}$ to the critical point as well as capturing the low-density behavior of hydrazine (as an ideal gas). However, the model does not correctly predict the constant pressure heat capacity $\left(C_{p}\right)$ of hydrazine; this suggests changes to the state equation in later studies will be necessary [14].

Elts et al. [15] used a combination of quantum chemistry and empirical refinements to determine the density, vapor pressure, heat capacity, second virial coefficient, shear viscosity, and isobaric liquid-vapor phase equilibrium for neat 
hydrazine, MMH, UDMH and mixtures of the same as well as with water or ammonia. Incorporation of the molecular geometry, (including interaction sites), electrostatics, and Lennard-Jones potential into the model, allows accurate prediction of the density, heat capacity, viscosity and isobaric liquid-vapor phase equilibria for the neat and binary systems. The second virial coefficient (in a power series approximation of pressure) was correctly predicted for neat hydrazine and predictions of this coefficient for MMH and UDMH were also made, but experimental measurements for these two species were unavailable to the authors. Another prediction made by in the Elts et al. [15] model is the azeotrope for hydrazinewater and $\mathrm{MMH}$-water systems, while also predicting the lack of an azeotrope for the UDMH-water system. The equation of state in this model was based on the Peng-Robinson equation with a quadratic Van der Waals, one-fluid mixing rule to incorporate experimental data.

Since many combustion reactions are studied using shock tube experiment, a detonation study of hydrazine decomposition was performed by Catoire et al. [16]. Incorporating the thermodynamic constants from these experiments into CHEMKIN, a kinetic decomposition model for hydrazine was prepared using KINALC software, with 33 reversible reactions and 13 species. The radical $\mathrm{N}_{2} \mathrm{H}_{3}$ is one of the most important species in this reaction [16]. Similarly, Daimon et al. [17] determined; by way of transition state theory and $a b$-initio quantum chemical modeling, that $\mathrm{N}_{2} \mathrm{H}_{3}$ was an important radical in the reaction between hydrazine and NTO. The study was performed under a static pressure of $10 \mathrm{~atm}$ with perfect mixing of the components. It was noted by Daimon et al. [17] that the chemical kinetics derived solely from shock tube experiments include a chainbranching mechanism resulting from the decomposition of the reactants, which will not occur at low temperatures [17]. Therefore, new models are required which incorporate lowtemperature reaction pathways.

In two quantum chemical modeling studies by Sun and Law [18] and Zhang et al. [19] the decomposition of $\mathrm{MMH}$ in the absence of additional reactants. Both studies identified the importance of $\mathrm{N}-\mathrm{N}$ and $\mathrm{C}-\mathrm{N}$ bond scission in the decomposition of MMH $[18,19]$. However, the two models do not agree, with the Sun and Law [18] suggesting a faster decomposition reaction than the later Zhang et al. [19] model. The discrepancy was explained by Zhang et al. [19] as a result of the Sun and Law [18] model also including hydrogenabstraction mechanisms, which were not included in the Sun and Law [18] model. It was further shown in [18] that their model matched well with low-pressure (0.01-0.04 atm) shock tube experiments whereas the model in [19] matched well with atmospheric shock tube experiments. Thinking conceptually, at low pressure there are few inter-molecular collisions, and therefore the importance of radical reactions (including hydrogen abstraction) will be diminished, favoring instead unimolecular reactions such as $\mathrm{N}-\mathrm{N}$ and $\mathrm{C}-\mathrm{N}$ bond scission. Therefore the results of both $[18,19]$ make physical sense.

Shock tube experiments of $\mathrm{MMH}$ decomposition by $\mathrm{Li}$ et al. [20] and Cook et al. [21] verified that N-N bond scission to form $\mathrm{NH}_{2}$ radicals was the primary mechanism of MMH pyrolysis. The Cook et al. [21] study also identified the hydrogen-abstraction by $\mathrm{NH}_{2}$ radicals from $\mathrm{MMH}$ to form $\mathrm{NH}_{3}$ as another important decomposition mechanism [21]. When compared to the theoretical model of Zhang et al. [19], the experimental results of [20] match well if the decomposition rate predicted by [19] is reduced by approximately $40 \%$ [20].

Other simulations of hydrazine combustion, and its derivatives, with $\mathrm{N}_{2} \mathrm{O}_{4}$ or nitric acid have been performed, focusing on the identification of intermediate species with low activation energy formed through exothermic reactions $[10,17,22,23]$. In their model, Daimon et al. [17] proposed that on contact with $\mathrm{NTO}, \mathrm{N}_{2} \mathrm{H}_{4}$ breaks down into $\mathrm{N}_{2} \mathrm{H}_{3}$ by hydrogen abstraction. The $\mathrm{N}_{2} \mathrm{H}_{3}$ then forms adducts with $\mathrm{NO}_{2}$, a species with which $\mathrm{NTO}$ is in equilibrium [17]. Similar adduct reactions occur as further hydrogen atoms are abstracted forming $\mathrm{N}_{2} \mathrm{H}_{2}$, and other radicals [17]. The hydrogen abstraction model is capable of predicting hypergolic ignition because the abstraction process has low activation energy and is highly exothermic (both properties are required for hypergolic reaction). Despite the ignition prediction capability, the Daimon et al. [17] model is only applicable over a narrow range of temperatures and pressures [17].

As described previously, methyldiazene, dimethyl tetrazene and methyltriazene have been proposed as important intermediate species during the combustion of $\mathrm{MMH}$ with NTO [10]. Dimethyl tetrazines are most common when excessive quantities of $\mathrm{MMH}$ are burned. Under cold conditions methylhydrazine, dimethylhydrazine nitrate, and methylhydrazine azide are also likely to be present [10]. In a separate study, performed by Osmont et al. [22], quantum chemistry calculations predict the formation of three dimethyl tetrazines $\left(\mathrm{CH}_{3}\left(\mathrm{NH}_{2}\right) \mathrm{NN}\left(\mathrm{NH}_{2}\right) \mathrm{CH}_{3}\right.$, $\mathrm{CH}_{3} \mathrm{NHNHNHNHCH}_{3}$, and $\left.\mathrm{CH}_{3}\left(\mathrm{NH}_{2}\right) \mathrm{NNHNHCH}_{3}\right)$ for the $\mathrm{MMH}-\mathrm{NTO}$ reaction. Although these dimethyl tetrazines have not been studied empirically, their heats of formation were calculated to range from $258.6 \mathrm{~kJ} / \mathrm{mol}$ to $269.4 \mathrm{~kJ} / \mathrm{mol}$ and are expected to decompose exothermically as well [22]. This same study also predicts the formation of nitroso, nitrite, nitro, and nitrate derivatives of $\mathrm{MMH}$ preceding decomposition [22], much like how $\mathrm{N}_{2} \mathrm{H}_{3}$ radicals were proposed to make adducts with $\mathrm{NO}_{2}$ in [17]. The enthalpies of formation for the nitroso, nitrite, nitro, and nitrate derivatives of $\mathrm{MMH}$ are between $95.8 \mathrm{~kJ} / \mathrm{mol}$ and $387 \mathrm{~kJ} / \mathrm{mol}$, which are in contrast to the dimethyl tetrazines which form exothermically, and decompose endothermically, as previously described [22].

In addition to the various hydrazine and $\mathrm{MMH}$ derivatives predicted in $[17,22]$ the formation of isomers of $\mathrm{N}_{2} \mathrm{O}_{4}$ is also predicted to have a pronounced effect on its reaction with the hydrazines [23]. Simulations of the combustion of $\mathrm{N}_{2} \mathrm{H}_{4}$ with NTO using GAUSSIAN 03 have revealed that symmetrical-NTO $\left(\mathrm{O}_{2} \mathrm{NNO}_{2}\right)$, cis-NTO $(\mathrm{ON}-$ $\mathrm{ONO}_{2}$ ), and $\mathrm{NO}_{2}$ have $14.2 \mathrm{kcal} / \mathrm{mol}, 10.6 \mathrm{kcal} / \mathrm{mol}$, and $7.6 \mathrm{kcal} / \mathrm{mol}$ activation barriers, respectively, to overcome in order to react with hydrazine [23]. However, hydrazine can induce the ionization of cis- and trans-NTO; cis$\mathrm{ONONO}_{2}$ and trans-ONONO${ }_{2}$, to spontaneously produce $\left[\mathrm{ON}^{+}\right]\left[\mathrm{ONO}_{2}{ }^{-}\right]$. Nitric acid and $\mathrm{H}_{2} \mathrm{NN}(\mathrm{H}) \mathrm{NO}$ are later formed when the $\left[\mathrm{ON}^{+}\right]\left[\mathrm{ONO}_{2}^{-}\right]$and $\mathrm{N}_{2} \mathrm{H}_{4}$ undergo 
metathetical reactions; a reaction where active groups are exchanged. The $\mathrm{H}_{2} \mathrm{NN}(\mathrm{H}) \mathrm{NO}$ molecule is formed on the order of $10^{-10} \mathrm{~cm}^{3} /$ molecule/s above $250 \mathrm{~K}$ and then undergoes exothermic decomposition to form $\mathrm{N}_{2} \mathrm{H}_{3}$ and either $\mathrm{N}_{2} \mathrm{O}_{4}$ or $\mathrm{NO}_{2}$. The rate constant for $\mathrm{N}_{2} \mathrm{H}_{3}$ radical production is on the order of $10^{7} / \mathrm{s}$, at $1000 \mathrm{~K}$, which is rapid enough to initiate hypergolic chain reactions with $\mathrm{NO}_{2}$ and $\mathrm{N}_{2} \mathrm{O}_{4}$ [23].

Although molecular dynamics studies and quantum chemistry are capable of explaining, in part, the processes and chemical reactions that take place in the hypergolic reactions of hydrazines, these models are not yet capable of accurately predicting performance characteristics (specific impulse, ignition delay, etc.), or recommending potential hypergolic components. In developing better hypergolic propellants there are two different aspects to be explored: improving performance and reducing hazards. Currently, much research is being done on replacing hydrazines with more environmentally friendly and less hazardous materials, but while these technologies are still being developed work continues on improving hydrazine-based propellants.

One proposed method to improve the safety of hydrazinebased propellants is to gel the hydrazine, and thereby reduce the vapor pressure, sensitivity, fire hazards, and leakage potential while increasing the specific energy density [24]. Hydrazine gelled with polysaccharides form shear-thinning gels and gels produced between NTO and silica form shearthinning thixotropic gels. Despite some safety improvement, the gelation of hydrazine and NTO can reduce the performance characteristics of the mixtures. The gelation of NTO with silica produces the most severe reduction in performance (from $275 \mathrm{~s}$ to $263 \mathrm{~s}$ ) because the silica does not contribute to the oxidation process, unlike the polysaccharide, which acts as a secondary fuel. The efficiency of the propellant is also decreased slightly by gelation, as revealed in 100-N thruster tests where the $\mathrm{C}^{*}$ combustion efficiency of neat hydrazine-NTO is $95 \%$, but is closer to $90 \%$ for the gelled mixture [24].

One way of boosting the gel performance is the addition of colloidal metal suspensions, such as aluminum, to the system. Gelation of UDMH with methylcellulose (3\%) burned with $\mathrm{N}_{2} \mathrm{O}_{4}$ has a theoretical vacuum Isp of $287.6 \mathrm{~s}$ at $70 \mathrm{~kg} / \mathrm{sq} \cdot \mathrm{cm}$ and $\mathrm{O} / \mathrm{F}$ of 1.5 [25]. The addition of $30 \%$ aluminum particles to the mixture increases the vacuum Isp to $316.7 \mathrm{~s}$ under the same conditions. Kerosene gels have a similar performance boost from $293.2 \mathrm{~s}$ to $302.9 \mathrm{~s}$ at $\mathrm{O} / \mathrm{F}$ equal to two [25]. Ignition delay tests for gelled hypergolic propellants still need to be conducted in order to determine if they are still viable. Another possibility for the continued used of hydrazines is the use of solid hydrazine derivatives in hybrid propellant applications. Jain [26] performed a review of this work, however, hybrid rocket propellants and work performed before 1990 is beyond the scope of the present report.

Another means to improve performance of hypergolic propellants is improving engine design. Nusca and McQuaid [27] have developed a reactive flow fluid dynamics model for the Impinging Stream Vortex Engine (IVSE) [27]. This new type of engine was designed to improve the mixing of gelled fuel and oxidizer by impinging a series of fuel and oxidizer streams radially at an angle to one another to induce swirl in the motor. Within this model quantum chemical simulations of the $\mathrm{MMH}-\mathrm{NO}_{2}$ reaction were included as both single-step, and finite reaction rate reactions. The results of the quantum chemistry simulation suggested that the reason $\mathrm{MMH}$ has a shorter ignition delay than hydrazine is the lower activation energy for hydrogen abstraction for $\mathrm{MMH}$. In a separate portion of their study, Nusca and McQuaid [27] suggested that chemicals which have lone electron pairs aligned with the $\mathrm{C}-\mathrm{N}$ bond will have shorter ignition delays when mixed with IRFNA than chemicals whose lone pairs are misaligned [27]. However, this hypothesis was not confirmed experimentally.

\section{Hydrogen Peroxide-Based Hypergolics}

In an attempt to replace hydrazines with low- or no-toxicity fuels and oxidizers, significant research has been undertaken to utilize high purity hydrogen peroxide $\left(\mathrm{H}_{2} \mathrm{O}_{2}\right)$, known as HTP (high test peroxide) or RGHP (rocket grade hydrogen peroxide) [28-36]. Hydrogen peroxide is especially proficient as a nontoxic propellant; decomposing into oxygen and water. In this research there are two major types of fuels that react with the hydrogen peroxide: catalytically driven fuels and reaction driven fuels. In the former, a fuel with suspended catalyst is prepared such that the catalyst decomposes the hydrogen peroxide into oxygen and water, and these products then react with the main fuel. In reaction driven fuels the hydrogen peroxide reacts directly with the fuel [28]. In either case, the main fuel is typically miscible with the oxidizer, allowing rapid and intimate mixing of the two [28-31].

Among the catalytically driven fuels are Block 0 [2830] (a mixture of methanol and manganese oxides), or salts of $\mathrm{Co}^{+2}, \mathrm{Co}^{+3}, \mathrm{Cu}^{+1}, \mathrm{Cu}^{+2}, \mathrm{Fe}^{+2}, \mathrm{Fe}^{+3}, \mathrm{Mn}^{+2}, \mathrm{Mn}^{+3}, \mathrm{Ag}^{+1}$, $\mathrm{Ru}^{+2}, \mathrm{~V}^{+2}$ suspended in a fuel such as kerosene [31-33]. With the exception of copper (II) acetylacetonate, the salts of manganese, copper, and iron tested were particularly reactive with $90 \%$ hydrogen peroxide [31-33]. Manganese (III) compounds react faster than manganese (II) compounds in open cup ignition test, as do cobalt (II) salts over cobalt (III) [33]. Open cup tests also suggest that iron compounds may have long ignition delays with $90 \%$ hydrogen peroxide [33]. Higher concentrations of hydrogen peroxide (94-98\%) may be needed to decrease the ignition delay of HTP-hypergols [29]. Increasing the initial combustion chamber pressure will decrease the ignition delay. However, if the ambient gas has a high thermal diffusivity/high mass diffusivity like helium the ignition delay will increase, or may even quench the reaction by drawing off heat more efficiently [29]. Despite being hypergolic with HTP, catalytically driven fuels tend to have longer ignition delays and lower impulses than reaction driven fuels. Increasing the catalyst loading may lead to reduction in ignition delay, but at the expense of impulse [28]. This is largely due to the increase in condensed exhaust species, which do not contribute to impulse [28]. Another drawback to catalytically-driven hypergolic propellants is the precipitation of the catalyst out of the solution which could lead to clogging of pipes and other problems associated with inhomogeneous propellants. 
Reaction driven fuels generally have lower ignition delays than catalytically driven fuels because more energy is released when hydrogen peroxide burns with a fuel than when it is catalytically decomposed [28]. Ethanolamine is a fuel which is known to react hypergolically in the presence of $90 \%$ hydrogen peroxide, without need for a catalyst [31, 32, 34]. However, when catalyzed with a $5 \% \mathrm{CuCl}_{2}$, ethanolamine can react hypergolically with $85 \% \mathrm{H}_{2} \mathrm{O}_{2}$ within $200 \mathrm{~ms}$, and within $30 \mathrm{~ms}$ with $10 \% \mathrm{CuCl}_{2}$ [34]. Pyrrole will also react hypergolically with $\mathrm{HTP}$ with or without $\mathrm{CuCl}_{2}[32,33,35]$. However, storage of catalyzed pyrrole leads to polymerization of the fuel $[31,32]$. It has also been observed that the ignition delays of the ethanolamine mixtures are sensitive to temperature, but the effect of oxidizer temperature appears minimal [34]. DMAZ (2-dimethylaminoethyl aide) has also been considered as a reaction-driven fuel for hydrogen peroxide, with which it reacts violently; however, the reaction is not violent enough to ignite hypergolically $[31,32]$. The reaction-driven hypergolic activity of TEA (triethylaluminum, a pyrophoric organometallic liquid) has also been confirmed with HTP; $25 \%$ TEA in hexane will ignite with 90\% RGHP. TEA/hexane is one of the few nonmiscible fuels known to spontaneously ignite with $\mathrm{H}_{2} \mathrm{O}_{2}[31,32]$.

Limited research has also been conducted in the application of pyrophoric materials (air hypergols) as hypergolic fuels. Both [31, 32] explored the use of $25 \%$ triethylaluminum (TEA) in hexane, where it hypergolically ignited with $\mathrm{H}_{2} \mathrm{O}_{2}$ $[31,32]$. Various gaseous and liquid silicon hydrides (silanes) were examined using thermodynamic codes for their propensity as propellants with $\mathrm{H}_{2} \mathrm{O}_{2}$ [35]. As the silanes have positive heats of formation, these materials have a wide range oxidizer-fuel ratios leading to high-impulse [35]. Specific impulses approximately $10 \%$ greater than $\mathrm{MMH} / \mathrm{NTO}$ at $3371 \mathrm{~N} * \mathrm{~s} / \mathrm{kg}$ and $3161 \mathrm{~N} * \mathrm{~s} / \mathrm{kg}$ were reported for $\mathrm{SiH}_{4}-98 \%$ HTP and $\mathrm{Si}_{5} \mathrm{H}_{14}-98 \%$ HTP, respectively. However, hypergolic ignition between silanes and hydrogen peroxide has yet to be confirmed experimentally [35].

Another type of hydrogen peroxide propellant was described in [36] where $\mathrm{H}_{2} \mathrm{O}_{2}$ is decomposed catalytically before the products combust with the fuel [36]. This type of thruster is based on the technology used for HTP monopropellants. In this staged bipropellant system the peroxide is fed through a catalyst bed which decomposed the oxidizer into oxygen gas and high temperature steam. Downstream of this catalyst bed the fuel, such as kerosene, is introduced and burned in the combustion chamber. Although this type of staged combustion mechanism is highly efficient $\left(\mathrm{C}^{*}\right.$ of $90 \%$ ), it is sensitive to the fuel injection system where fuel injection at the edge of the injector plate provides the highest efficiency. The pressure rises (ignition delay) in the combustion chamber for this type of propellant nonetheless rather slow [36].

An additional class of reaction-driven hypergolic fuels for hydrogen peroxide includes ionic liquids (IL) and metal hydrides [37-39]. Thermodynamical studies of the combination of metal hydrides and HTP have shown the potential for HTP-lithium borohydride, HTP-lithium aluminum hydride and HTP-lithium aluminum hexahydride propellants to have density Isp as high as $460 \mathrm{~kg} * \mathrm{~s} / \mathrm{m}^{2}, 480 \mathrm{~kg} * \mathrm{~s} / \mathrm{m}^{2}$, and
$590 \mathrm{~kg} * \mathrm{~s} / \mathrm{m}^{2}$, respectively [37]. For HTP-lithium borohydride the density-Isp comparable to NTO-MMH or HTPBlock 0; the calculated impulses of HTP with lithium aluminum hydride and lithium aluminum hexahydride propellants exceed NTO-MMH. An experimental study on these metal hydrides performed by Pourpoint and Rusek [37], has demonstrated that complexes of aluminum hydride and aluminum borohydride with trihexyltetradecylphosphonium will react hypergolically with HTP [38]. Neat aluminum hydride does not react with either WFNA or $\mathrm{N}_{2} \mathrm{O}_{4}$, but aluminum borohydride will ignite with all three oxidizers (WFNA, $\mathrm{N}_{2} \mathrm{O}_{4}$, HTP) [32]. With either $90 \%$ or $98 \% \mathrm{H}_{2} \mathrm{O}_{2}$, aluminum hydride ignites after approximately $3 \mathrm{~s}$ while aluminum borohydride ignites within $30 \mathrm{~ms}$ [38]. Despite being nontoxic and easily handled, hydrogen peroxide-based propellants suffer from limitations inherent to the oxidizer, namely a high freezing temperature $[2,34]$. Either a means of depressing the freezing point of HTP or a separate oxidizer for low temperature applications may be required.

\section{Other Propellant Formulations}

The use of ionic liquids (IL) and borides was also explored as potential propellants, but with nitric acid instead of hydrogen peroxides. The ignition delays of methylimidazolium dicyanamides with various functional groups (allyl, 3-butenyl, and propargyl) were measured by Schneider et al. [39]. Allyl- and propargyl-methylimidazolium dicyanamide salts are hypergolic with both WFNA and IRFNA, with ignition delays of $43 \mathrm{~ms}$ and $15 \mathrm{~ms}$ with WFNA, respectively, and $625 \mathrm{~ms}$ and $170 \mathrm{~ms}$ ignition delays with IRFNA, respectively. The 1-butyl3-methyl- salts of imidazolium and pyridinium and 1-butyl1-methyl-pyrrolidinium were also tested for their hypergolic activity with WFNA and had ignition delays between 31 and $47 \mathrm{~ms}$ [39].

Ignition delay studies of ammonia borane, hydrazine borane, and hydrazine bis-borane dissolved in the ILs 1-butyl-3-methyl-imidazolium tetrafluoroborate $\left(\mathrm{bmimBF}_{4}\right), 1-$ butyl-3-methylimidazolium dicyanamide (bmimDCA) and 1-butyl-1-methyl pyrrolidinium dicyanamide ( $\left.\operatorname{Pyrr}_{14} \mathrm{DCA}\right)$ with WFNA have also been performed [40]. The neat solids (ammonia borane, hydrazine borane, and hydrazine bisborane) have ignition delays of $80 \mathrm{~ms}, 4 \mathrm{~ms}$, and $12 \mathrm{~ms}$, respectively. In solution with bmimBF$_{4}$ the ignition delays increase to $88 \mathrm{~ms}$ (ammonia borane), $390 \mathrm{~ms}$ (hydrazine borane), and nonhypergolic (hydrazine bis-borane), but decrease in either bmimDCA or Pyrr ${ }_{14}$ DCA to as little as $3 \mathrm{~ms}$ [40].

Another ionic liquid which is being explored as a potential propellant is 1-ethyl-3 methylimidazolium perchlorate ([emim $]\left[\mathrm{ClO}_{4}\right]$, or $\left.\left[\mathrm{C}_{6} \mathrm{H}_{11} \mathrm{~N}_{2}{ }^{+}\right]\left[\mathrm{CLO}_{4}{ }^{-}\right]\right)$[41, 42]. A modeling study by Williams [41] has suggested that this ionic liquid used as a monopropellant should have an Isp of $228 \mathrm{~s}$, which is the same as hydrazine [41]. At room temperature the salt is liquid with a melting point between $16.8^{\circ} \mathrm{C}$ (onset of melting) and $24.7^{\circ} \mathrm{C}$ (peak melting temperature) [42]. The onset of decomposition of $[\mathrm{emim}]\left[\mathrm{ClO}_{4}\right]$ is $186^{\circ} \mathrm{C}$, and will not explode when a $5 \mathrm{~kg}$ mass is dropped from a height of $0.8 \mathrm{~m}$ onto it, nor when $360 \mathrm{~kg}$ is dragged across its surface in 
friction testing [42]. "Heavy deflagration" but not detonation were confirmed with $[\mathrm{emim}]\left[\mathrm{ClO}_{4}\right]$ during small-scale-fastcookoff tests [42]. While $[\mathrm{emim}]\left[\mathrm{ClO}_{4}\right]$ has not yet been examined for hypergolicity with any oxidizer, other pyrrole and diazole ionic compounds $[40,41]$ are known hypergolic components and consequently merit further research.

As with hydrazine fuels, there is a need for a general theory to explain how a combination of fuel and oxidizer ignite spontaneously, as well as a thermodynamical approach to estimate the ignition delay. Such a model has been prepared for gelled propellants by Gao and Shreeve [40] using a onestep Arrhenius interface reaction of the zeroth order. By defining a thermal, responsivity, (a combination of thermal conductivity and thermal diffusivity), and coalescing transient heat conduction, activation energy asymptotics with nondimensional time a generalized heat transfer equation was produced which predicts the time to thermal runaway. At the thermal runaway point the ignition of the propellant combination occurs. The general ignition temperature equation (1) is

$$
t_{\text {ign }}=\frac{c}{\pi}\left[\frac{\left(\lambda_{F} / \sqrt[2]{\alpha_{F}}+\lambda_{\mathrm{O}} / \sqrt[2]{\alpha_{\mathrm{O}}}\right) R T_{t_{o}}}{E Q e^{-E / R T_{t_{o}}}}\right],
$$

where $\lambda$ is the thermal conductivity, $\alpha$ is the thermal diffusivity, $R$ is the gas constant, $T_{t_{o}}$ is the interface temperature, $E$ is the overall activation energy, $Q$ is the exponential prefactor, and the subscripts $F$ and $O$ refer to the fuel and oxidizer, respectively [40]. The value $c$ is a universal constant born out of the activation energy asypmtotics, and is approximately 1.5.

\section{Conclusions}

In this review, three major topics in hypergolic propellant research since 1990 have been considered: ignition delay testing methods, hydrazine-based hypergols, and efforts to produce hydrazine-free hypergols. In regards to measuring ignition delay there are three types of ignition delay testing, drop testing, impinging jet, and engine tests. Because drop methods do not provide engine-like mixing conditions, it is recommended that this test be used preliminary screening of novel propellant formulation. If desired, a two-step approach may be implemented where the first measurements are qualitative (i.e., does the mixture ignite) before measuring ignition delays quantitatively. After promising formulas are identified, further testing utilizing an impinging jet apparatus should be performed.

A two-stage approach may be appropriate here as well, with the first stage performed under ambient atmosphere (to assess ignition delay as a result of enhanced mixing). The second stage would be under extreme conditions such as high thermal conductivity and low pressure atmosphere, thereby ensuring reasonable ignition delays sans atmosphere. Both drop tests and impinging jet tests would benefit spectroscopic methods by providing insight into reaction kinetics involved in hypergolic ignition. The final stage, engine testing, would then be performed only on the most promising hypergols, as engine tests use large volumes of fuel and oxidizer and are therefore expensive to perform.
In regards to hydrazine-based propellants, it was shown that there are two main directives in the literature: an effort to build more accurate models to predict hypergolic activity and efforts to reduce hydrazine toxicity. Many current models of hydrazine ignition are based on high temperature species and reactions based on shock tube experiments. Although these models tend to predict hypergolic ignition, the reactions may be nonphysical because preignition is low temperature, and shock tube experiments produce temperatures often in excess of $1000 \mathrm{~K}$. Therefore, new analysis techniques and subsequent models are needed to describe the preignition mechanisms resulting in hypergolicity. Ignition delay methods (i.e., drop testing) incorporating spectroscopic methods will aid in modeling efforts since these are typically performed at ambient temperatures.

As for reducing toxicity and vapor pressure or increasing formulation density of hydrazine-based propellants, gelation may be a viable option. However, higher energy gellants for hydrazines, or oxygen-rich gellants for NTO and/or $\mathrm{HNO}_{3}$ should be explored to maintain high specific impulses. Gellants which contribute to the combustion (e.g., a polysaccharide or reactive metal colloids for fuels, or oxygen-bearing compounds for oxidizers) are preferable to inert (e.g., silica) gellants which will not produce gas or heat and therefore thrust. Oxygen-rich gellants for NTO and other oxidizers will minimize the gellant's effect on the oxygen balance of the formulation. Long-term stability, changes to ignition delay and specific impulse, and reaction stability should all be addressed for new formulations. Gelation may also be suitable for novel, hydrazine-free hypergolic formulations.

Hydrogen peroxide is the primary oxidizer being explored for hypergolic alternatives to hydrazine-based propellants. For maximum performance, a fuel which reacts with hydrogen peroxide without a catalyst should be explored. Adjustment of the ignition delay may then be considered through addition of a miscible catalyst. At present, there appears to no class of materials which stands out as candidate fuels for $\mathrm{H}_{2} \mathrm{O}_{2}$ hypergols, except that the fuel should be miscible with water. Ionic liquids and metal hydrides including boranes, silanes, and aluminum hydrides, however, show promise based on thermodynamic calculations. Known catalysts for $\mathrm{H}_{2} \mathrm{O}_{2}$ hypergols are primarily salts of transition metals; particularly manganese, iron, and copper. For optimum performance, these salts should be highly soluble in the selected fuel. Low freezing point oxidizers should also be considered for hypergolic propellants.

\section{Conflict of Interests}

The authors declare that there is no conflict of interests regarding the publication of this paper.

\section{References}

[1] S. R. Turns, An Introduction to Combustion: Concepts and Applications, McGraw-Hill, Boston, Mass, USA, 2nd edition, 2000.

[2] G. P. Sutton, Rocket Propulsion Elements: An Introduction to the Engineering of Rockets, John Wiley \& Sons, New York, NY, USA, 2nd edition, 1956. 
[3] L. O. Mays, Analysis of chemical delay time in hypergolic fuels [M.S. thesis], University of Alabama, Huntsville, Ala, USA, 1998.

[4] M. J. Farmer, L. O. Mays, C. S. Hampton, and J. E. Smith Jr., "Reaction rates for hypergolic propellants using chemical delay times," Journal of Propulsion and Power, vol. 20, no. 2, pp. 372376, 2004.

[5] S. Q. Wang and S. T. Thynell, "An experimental study on the hypergolic interaction between monomethylhydrazine and nitric acid," Combustion and Flame, vol. 159, no. 1, pp. 438-447, 2012.

[6] A. J. Alfano, J. D. Mills, and G. L. Vaghjiani, "Highly accurate ignition delay apparatus for hypergolic fuel research," Review of Scientific Instruments, vol. 77, no. 4, Article ID 045109, 2006.

[7] Z. Slocum-Wang, L. D. Felton, T. W. Turner, and W. H. Stevenson III, "Ignition delay screening techniques: drop testing vs. engine testing," in Proceedings of the 42nd AIAA/ASME/ SAE/ASEE Joint Propulsion Conference \& Exhibit (AIAA '06), pp. 2352-2359, Sacramento, Calif, USA, July 2006.

[8] T. L. Pourpoint and W. E. Anderson, "Environmental effects on hypergolic ignition," in Proceedings of the 41st AIAA/ASME/ SAE/ASEE Joint Propulsion Conference and Exhibit, AIAA 20053581, pp. 1-15, Tuscon, Ariz, USA, 2005.

[9] A. Chowdhury, C. Bapat, and S. T. Thynell, "Apparatus for probing preignition behavior of hypergolic materials," Review of Scientific Instruments, vol. 80, no. 4, Article ID 044101, 2009.

[10] I. Frank, A. Hammerl, T. M. Klapötke, C. Nonnenberg, and H. Zewen, "Processes during the hypergolic ignition between monomethylhydrazine (MMH) and dinitrogen tetroxide $\left(\mathrm{N}_{2} \mathrm{O}_{4}\right)$ in rocket engines," Propellants, Explosives, Pyrotechnics, vol. 30, no. 1, pp. 44-52, 2005.

[11] B. Yenne, The Encyclopedia of US Spacecraft, Bison Books, Hong Kong, 1987.

[12] T. Edwards, "Liquid fuels and propellants for aerospace propulsion: 1903-2003," Journal of Propulsion and Power, vol. 19, no. 6, pp. 1089-1107, 2003.

[13] L. Catoire, N. Chaumeix, S. Pichon, and C. Paillard, "Visualizations of gas-phase NTO/MMH reactivity," Journal of Propulsion and Power, vol. 22, no. 1, pp. 120-126, 2006.

[14] D. Giordano and M. D. Serio, "Thermodynamic model of hydrazine that accounts for liquid-vapor phase change," Journal of Thermophysics and Heat Transfer, vol. 16, no. 2, pp. 261-272, 2002.

[15] E. Elts, T. Windmann, D. Staak, and J. Vrabec, "Fluid phase behavior from molecular simulation: hydrazine, Monomethylhydrazine, Dimethylhydrazine and binary mixtures containing these compounds," Fluid Phase Equilibria, vol. 322-323, pp. 7991, 2012.

[16] L. Catoire, J. Luche, G. Dupré, and C. Paillard, "Critical reactions for the hydrazine vapor detonations," Shock Waves, vol. 11, no. 2, pp. 97-103, 2001.

[17] Y. Daimon, H. Terashima, and M. Koshi, "Evaluation of rate constants relevant to the hypergolic reaction of hydrazine with nitrogen dioxide," in Proceedings of the 7th Mediterranean Combustion Symposium, Sardinia, Italy, 2011.

[18] H. Sun and C. K. Law, "Thermochemical and kinetic analysis of the thermal decomposition of monomethylhydrazine: an elementary reaction mechanism," Journal of Physical Chemistry A, vol. 111, no. 19, pp. 3748-3760, 2007.

[19] P. Zhang, S. J. Klippenstein, H. Sun, and C. K. Law, "Ab initio kinetics for the decomposition of monomethylhydrazine $(\mathrm{CH}$
3NHNH2)," Proceedings of the Combustion Institute, vol. 33, no. 1, pp. 425-432, 2011.

[20] S. Li, D. F. Davidson, and R. K. Hanson, "Shock tube study of the pressure dependence of monomethylhydrazine pyrolysis," Combustion and Flame, vol. 161, no. 1, pp. 16-22, 2014.

[21] R. D. Cook, S. H. Pyun, J. Cho, D. F. Davidson, and R. K. Hanson, "Shock tube measurements of species time-histories in monomethyl hydrazine pyrolysis," Combustion and Flame, vol. 158, no. 4, pp. 790-795, 2011.

[22] A. Osmont, L. Catoire, T. M. Klapötke, G. L. Vaghjiani, and M. T. Swihart, "Thermochemistry of species potentially formed during NTO/MMH hypergolic ignition," Propellants, Explosives, Pyrotechnics, vol. 33, no. 3, pp. 209-212, 2008.

[23] K.-Y. Lai, R. Zhu, and M. C. Lin, "Why mixtures of hydrazine and dinitrogen tetroxide are hypergolic?" Chemical Physics Letters, vol. 537, pp. 33-37, 2012.

[24] S. Rahimi, D. Hasan, and A. Peretz, "Development of laboratory-scale gel-propulsion technology," Journal of Propulsion and Power, vol. 20, no. 1, pp. 93-100, 2004.

[25] T. L. Varghese, S. C. Gaindhar, J. David et al., "Developmental studies on metallised UDMH and kerosene gels," Defence Science Journal, vol. 45, no. 1, pp. 25-30, 1995.

[26] S. R. Jain, "Spontaneously igniting hybrid fuel-oxidiser systems," Defence Science Journal, vol. 45, no. 1, pp. 5-16, 1995.

[27] M. J. Nusca and M. J. McQuaid, "Combustion chamber fluid dynamics and hypergolic gel propellant chemistry simulations for selectable thrust rocket engines," in Proceedings of the Users Group Conference (DOD_UDC '05), 2005.

[28] R. K. Palmer and J. J. Rusek, "Low toxicity reactive hypergolic fuels for use with hydrogen peroxide," in Proceedings of the 2nd International Conference on Green Propellants for Space Propulsion, pp. 199-204, Sardinia, Italy, June 2004.

[29] T. L. Pourpoint and W. E. Anderson, "Hypergolic reaction mechanisms of catalytically promoted fuels with rocket grade hydrogen peroxide," Combustion Science and Technology, vol. 179, no. 10, pp. 2107-2133, 2007.

[30] B. L. Austin, S. D. Heister, and W. E. Anderson, "Characterization of pintle engine performance for nontoxic hypergolic bipropellants," Journal of Propulsion and Power, vol. 21, no. 4, pp. 627-635, 2005.

[31] B. Melof and M. Grubelich, "Investigation of hypergolic fuels with hydrogen peroxide," in Proceedings of the 1st International Conference on Green Propellants for Space Propulsion, SP-284, SAND 2000-2842C, European Space Agency, 2001.

[32] D. L. Keese, W. R. Escapule, M. C. Grubelich, and J. A. Ruffner, "Hydrogen peroxide-based propulsion and power systems," SAND Report 2004-1327, U.S. Department of Energy, 2004.

[33] Y. Cong, T. Zhang, T. Li et al., "Propulsive performance of a hypergolic $\mathrm{H}_{2} \mathrm{O}_{2}$ /kerosene bipropellant," Journal of Propulsion and Power, vol. 20, no. 1, pp. 83-86, 2004.

[34] M. A. Ak, A. Ulas, B. Sümer et al., "An experimental study on the hypergolic ignition of hydrogen peroxide and ethanolamine," Fuel, vol. 90, no. 1, pp. 395-398, 2011.

[35] B. Hidding, M. Pfitzner, and S. D. Bruno, "Silanes $/ \mathrm{H}_{2} \mathrm{O}_{2}-$ a high-performance synthetic bipropellant for chemical space propulsion," Journal of Propulsion and Power, vol. 24, no. 1, pp. 150-154, 2007.

[36] S. Jo, S. An, J. Kim, H. Yoon, and S. Kwon, "Performance characteristics of hydrogen peroxide/kerosene staged-bipropellant 
engine with axial fuel injector," Journal of Propulsion and Power, vol. 27, no. 3, pp. 684-691, 2011.

[37] T. L. Pourpoint and J. J. Rusek, "Novel organometallic propellants for hypergolic applications," Swift Enterprises Report, Swift Enterprises, West Lafayette, Ind, USA, http://www.sps .aero/Key_ComSpace_Articles/LibTech/LIB-035_Novel_Organometallic_Propellants_for_Hypergolic_Applications .pdf.

[38] S. Schneider, T. Hawkins, Y. Ahmed, M. Rosander, L. Hudgens, and J. Mills, "Green bipropellants: Hydrogen-rich ionic liquids that are hypergolic with hydrogen peroxide," Angewandte Chemie-International Edition, vol. 50, no. 26, pp. 5886-5888, 2011.

[39] S. Schneider, T. Hawkins, M. Rosander, G. Vaghiiani, S. Chambreau, and G. Drake, "Ionic liquids as hypergolic fuels," Energy \& Fuels, vol. 22, no. 4, pp. 2871-2872, 2008.

[40] H. Gao and J. M. Shreeve, "Ionic liquid solubilized boranes as hypergolic fluids," Journal of Materials Chemistry, vol. 22, no. 22, pp. 11022-11024, 2012.

[41] F. A. Williams, "Simplified theory for ignition times of hypergolic gelled propellants," Journal of Propulsion and Power, vol. 25, no. 6, pp. 1354-1356, 2009.

[42] T. M. Klapötke, J. Stierstorfer, H. D. Brooke Jenkins, R. van Eldik, and M. Schmeisser, "Calculation of some thermodynamic properties and detonation parameters of 1-ethyl-3-methyl$\mathrm{H}$-imidazolium perchlorate, $[\mathrm{emim}]\left[\mathrm{ClO}_{4}\right]$, on the basis of CBS-4M and CHEETAH computations supplemented by VBT estimates," Zeitschrift für Anorganische und Allgemeine Chemie, vol. 637, no. 10, pp. 1308-1313, 2011. 

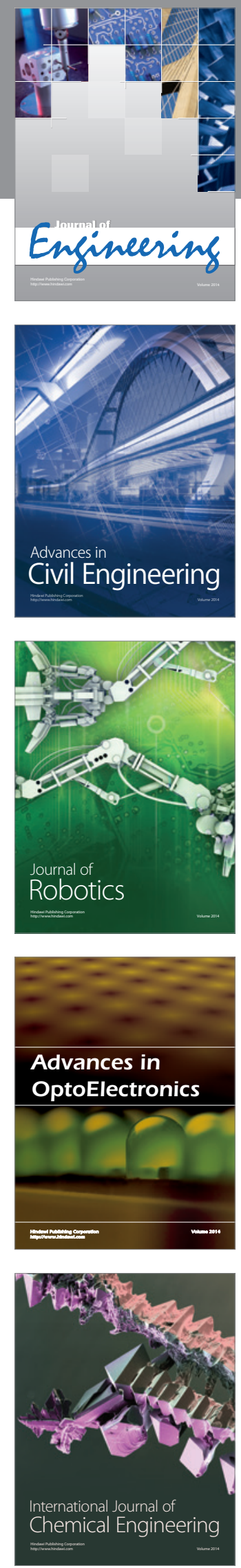

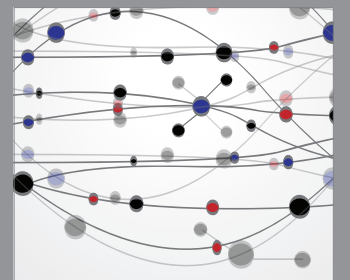

The Scientific World Journal
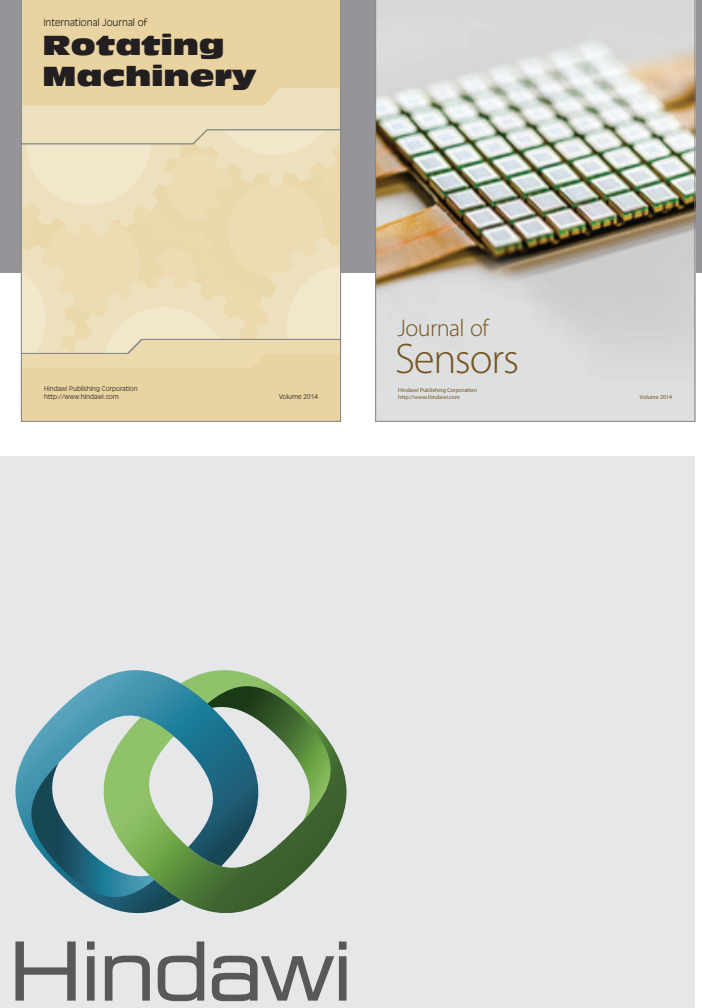

Submit your manuscripts at http://www.hindawi.com
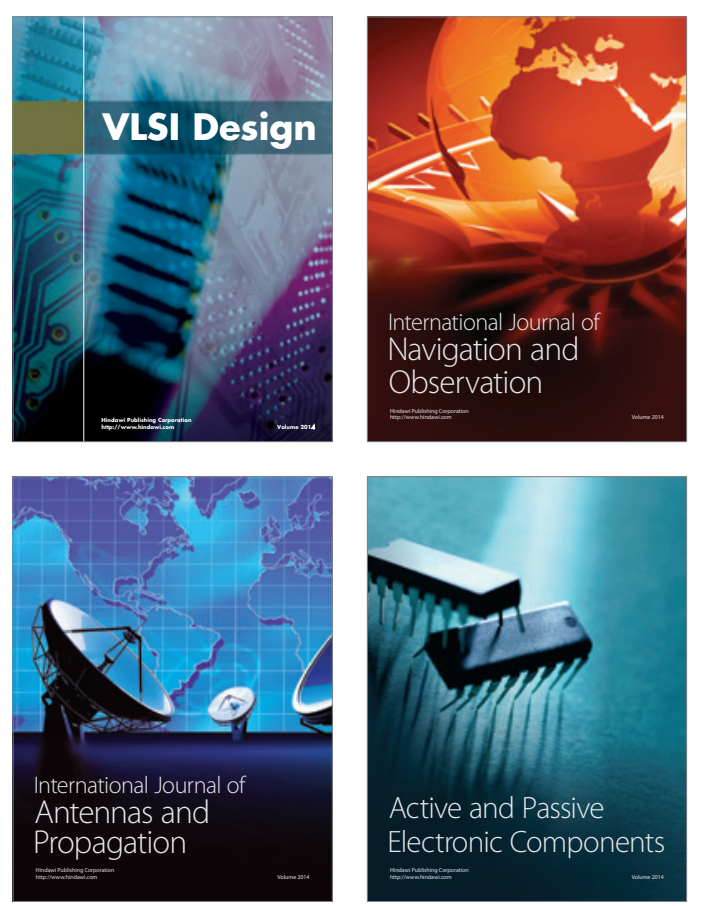
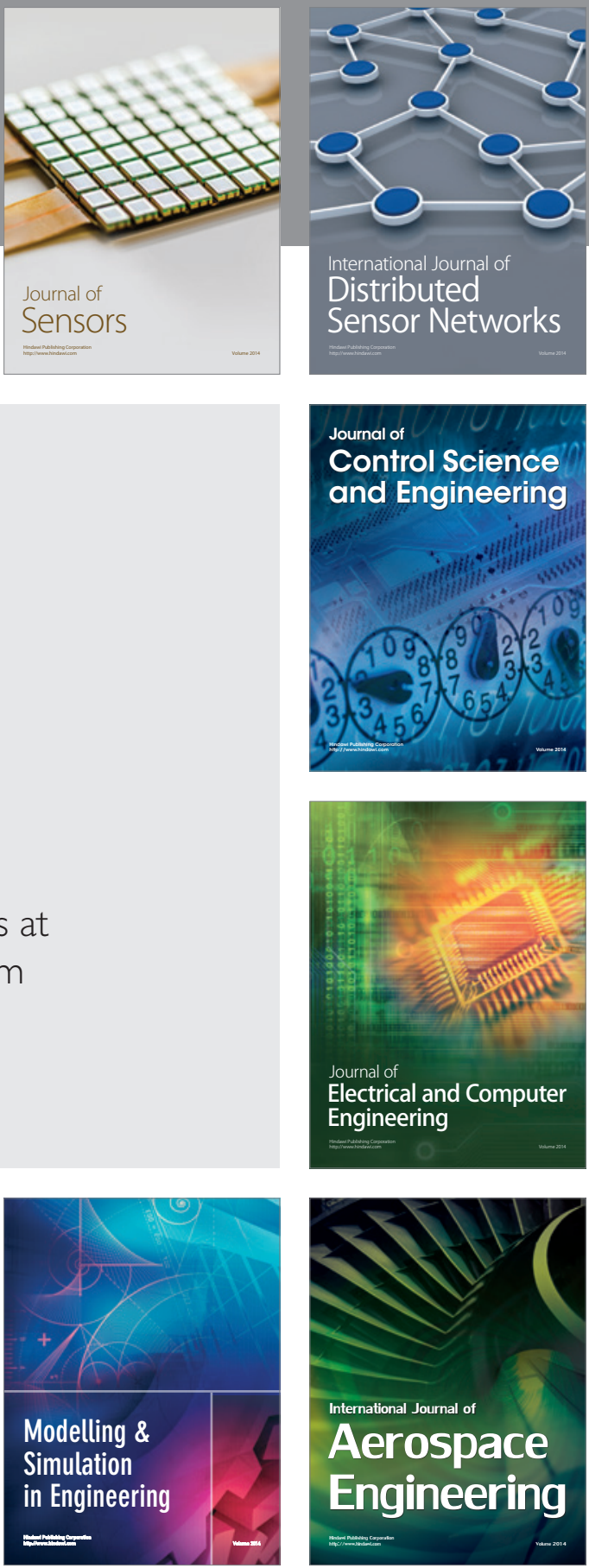

Journal of

Control Science

and Engineering
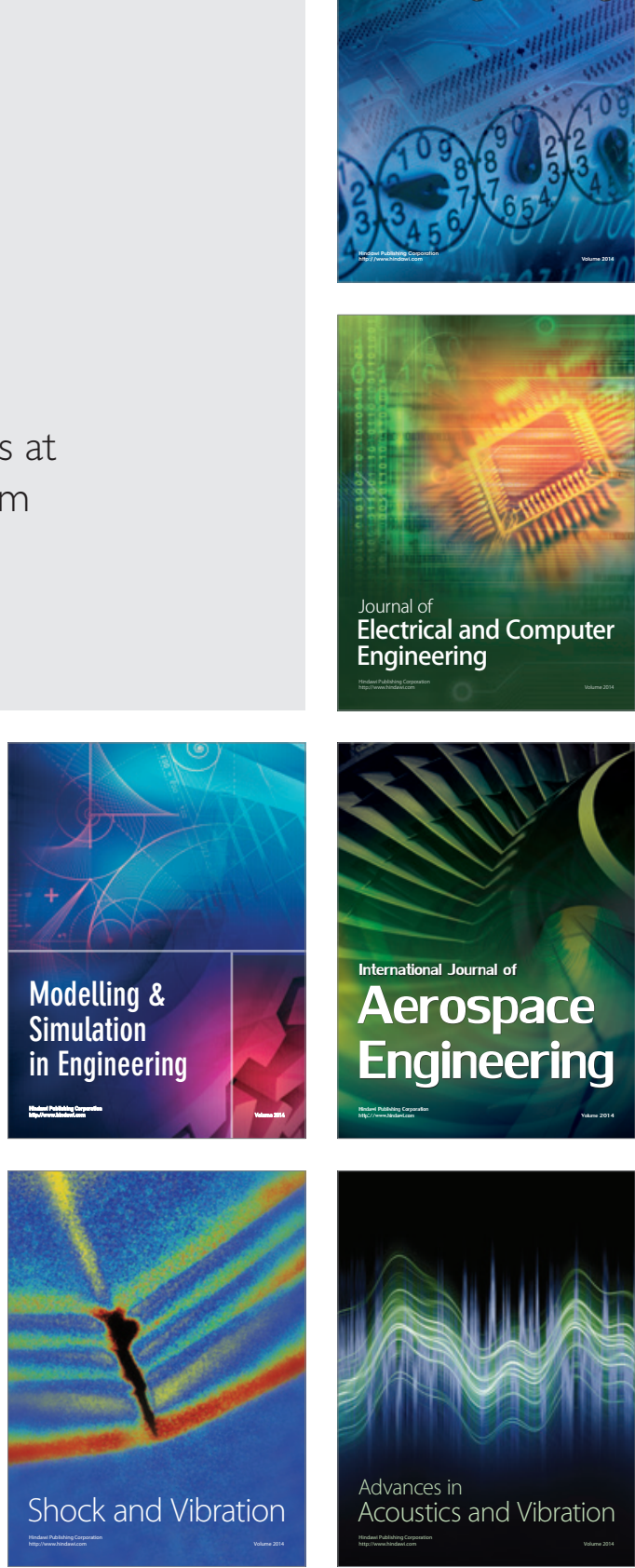